\title{
DEVELOPMENT OF FOREIGN LANGUAGE PROFICIENCY ASSESSMENT AND CONTROL METHODS IN HETEROGENIOUS GROUPS OF ADULT LEARNERS IN FURTHER EDUCATION AS A TOOL TO INCREASE STUDENTS' MOTIVATION
}

\author{
Maria Vladimirovna Zarudnaya ${ }^{1}$, Oksana Ivanovna Barsova ${ }^{2}$
}

\begin{abstract}
The educational system in the Russia provides opportunities for life-long learning, which presupposes availability of studying foreign languages at every stage, including further education (MBA and Presidential Program). Although adult learners realize the importance and necessity of mastering a foreign language, they might lack motivation due to a number of factors, such as different sociocultural backgrounds, social status, lifestyle, and knowledge of the foreign language. We have conducted research in order to analyze existing problems and develop a system of tasks to control and assess progress in a foreign language (English) proficiency in heterogeneous groups of adult learners. The developed approach to designing assessment materials is aimed not only at controlling students’ progress, but also at increasing their motivation.
\end{abstract}

UDC Classification: 374, DOI: http://dx.doi.org/10.12955/cbup.v2.468

Keywords: adult, foreign language, higher education, heterogeneous, assessment, motivation

\section{Introduction}

There is no doubt that the process of teaching is very complex, intricate, and always challenging. All teachers must be prepared to elaborate each lesson as well as improvise, and implement alterations during the course. Teaching adults is quite different compared to teaching children or younger students, and heterogeneity of groups makes the process even more complicated, not to mention developing methods for control and assessment of the learners' English language proficiency.

On the subject of our research, empathizing that education system in the Russia provides different opportunities for life-long learning, our applied sphere of analysis is limited to heterogeneous groups of adult learners in further education, mainly focusing on developing control and assessment materials that, alongside with monitoring students' progress, would increase their motivation to study a foreign language (English).

\section{Information on the research aspects of further education}

The system of further education in the Russia includes different types of programs, among which MBA programs and Presidential program are the most widespread. While MBA programs are very similar to most European MBA programs, but Presidential program is quite different in Russia.

In compliance with the Presidential Decree of July, 23, 1997 N774 "On Preparing Executives for National Economy of the Russian Federation" and the Government ordinance issued on March 24, 2007 N177 "About Training Executives for National Economy Organizations of the Russian Federation from 2007/08 - 2014/15," a large-scale unique program for educating senior executives in Russian national economy organizations was launched in 1998. Within the program there were three levels of training:

- Educational programs of professional retraining (550 hours - Level "B");

- Project-oriented programs of professional retraining (Higher Level “A”);

- Programs for advanced professional development, Departments: "Entrepreneurial Development” and “Management in Innovative Sphere” (120 hours, since 2010).

\footnotetext{
${ }^{1}$ Maria Vladimirovna Zarudnaya, Plekhanov Russian University of Economics, Russian Federation, marya_zarudnaya@mail.ru

${ }^{2}$ Oksana Ivanovna Barsova, Plekhanov Russian University of Economics, Russian Federation, barsovw2@mail.ru
} 
Teaching is provided by 102 universities in almost all of the regions in the Russian Federation. The target audience is graduate specialists with no less than 5 years of working experience, with at least 3 of which in a managerial position, and preferably up to 40 years of age. Since 2007, there has been three sources of funding: one source (33\%) is from the Federal budget; another source (33\%) is by Regional budget; the remaining $34 \%$ is paid by the companies sponsoring the executives or by selffunding. Initially, the Program was planned to be fully financed by the State budget until 2007.

\section{Issues associated with teaching and learning in heterogeneous groups of adult learners.}

First of all, we find it necessary to provide some explanations as to what are the heterogeneous groups. As it was mentioned before, we have examined groups of MBA students and Presidential program students. In both cases, language groups are formed based on the students' language proficiency; consequently, we considered that our students have more or less the same level of foreign language proficiency. However, almost all of the other individual characteristics of students are diverse and students in one group may have very little in common in terms of: age (from 25 to 54), social background, cultural background, area of employment, social status, previous experience, personal preferences, learning styles, time available for self-study, etc.

All of these allow us to treat our groups of adult students in further education as heterogeneous. Taking into account the mix of different characteristics that might be found in one group, which makes it obvious that a teacher encounters a lot of difficulties when teaching a foreign language to adult students in further education.

Problems concerning with teaching heterogeneous groups of adult learners are listed below.

- The age differences within one group. Such great difference (from 25 to 54 years old) is not found at any other stage of education and neither teachers nor students experience it in secondary or tertiary education.

- Some students lack confidence when using a foreign language, especially at the initial stage of learning as they feel anxious or embarrassed about making mistakes.

- Difference in students' expectation. Based on previous experience, many of them consider that classes would be organized in an academic manner, which is similar to the ones they used attend in school or university. This problem is prominent in adult groups as many of learners come not only from different universities, but also from different regions and cultures.

- Different learning styles (visual, audio, and kinesthetic) can also present difficulties for students. Some might feel more comfortable when listening to explanations or recordings, while others will always need some visual support. Besides, there are those who would prefer to interact in some activities.

- Irregular attendance makes the process of studying even more complicated for adult learners. Due to extensive workload, occasional business trips, and class absences, they not only lead to certain gaps in their learning, but also contribute to a loss of confidence.

In addition, various personal circumstances such as family commitments, health issues, personality traits, and individual learning capabilities also have negative influence on adult learners' progress and intensify complications for teachers as it becomes more problematic to form effective learning groups when students lack common grounds.

Besides, teachers encounter a number of other problems when teaching heterogeneous groups of adult learners.

First of all, the following pedagogical problems should be mentioned:

- communication tasks - teachers should adopt existing or develop their own tasks to make them relevant and meaningful for all students in a group; 
- tendency to avoid potentially difficult tasks-some students might be unhappy about doing challenging tasks, as they do not want to feel embarrassed if they fail.

The second group consists of organizational problems such as:

- difficulties in grouping students-it could be difficult to organize students' work in pairs or small groups as some of them might be reluctant to work with someone who of a different status or age;

- necessity to consider students' social status-when allocating tasks and roles in role-plays and simulations, some of them can be rather sensitive to such issues.

The third group consists of egotistical problems including:

- questioning of authority—some students might question their teacher's expertise and qualification, especially when the teacher is younger than the students.

\section{System of final control and assessment}

In order to minimize the impact of the problems identified above, we have developed a system of students' progress assessment that allows us to increase students' motivation, develop essential skills, and foster communication among students in heterogeneous groups of adult learners. The first step is to create a "needs analysis questionnaire" to determine how and where our students intend to use the English language and their preferences in classroom activities. Over a three-year period (2011-2013), we have compared the results received from the questionnaires completed by $145 \mathrm{MBA}$ and Presidential program students between the age of 27 and 54 with real situations observed in our classrooms (Figure 1) and have come to the following conclusions:

- students do not adequately identify their needs and level of language proficiency;

- students do not realize how much time and effort the learning process will take;

- students have overestimated their progress.

Figure 1: Evaluation of student's presentation skills

2012-2013

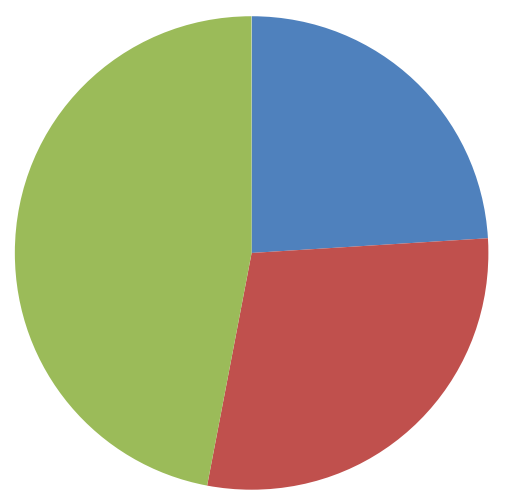

- Underestimated - 24\%

- Realistic - 29\%

- Overestimated - 47\%

Source: Authors

Moreover, we have discovered that during the course of study, students are mostly interested in preparing and delivering presentations, participating in negotiations, travelling and socializing, writing for business purposes, etc. The results are shown in Figure 2 and Figure 3.

Thus, we have developed a system of final assessment, which allows students to both demonstrate their skills acquired in the course of studies and participate in an evaluation of their fellow students. 
We split the whole process of final assessment into four stages. During the first stage, students have to analyze a case, which they discuss in mini groups. During the second stage, they must participate in negotiations to reach a common decision. The third stage involves writing a report on the results of negotiations and at the fourth, and final, stage they must prepare and deliver an individual presentation on one of the aspects outlined in the case.

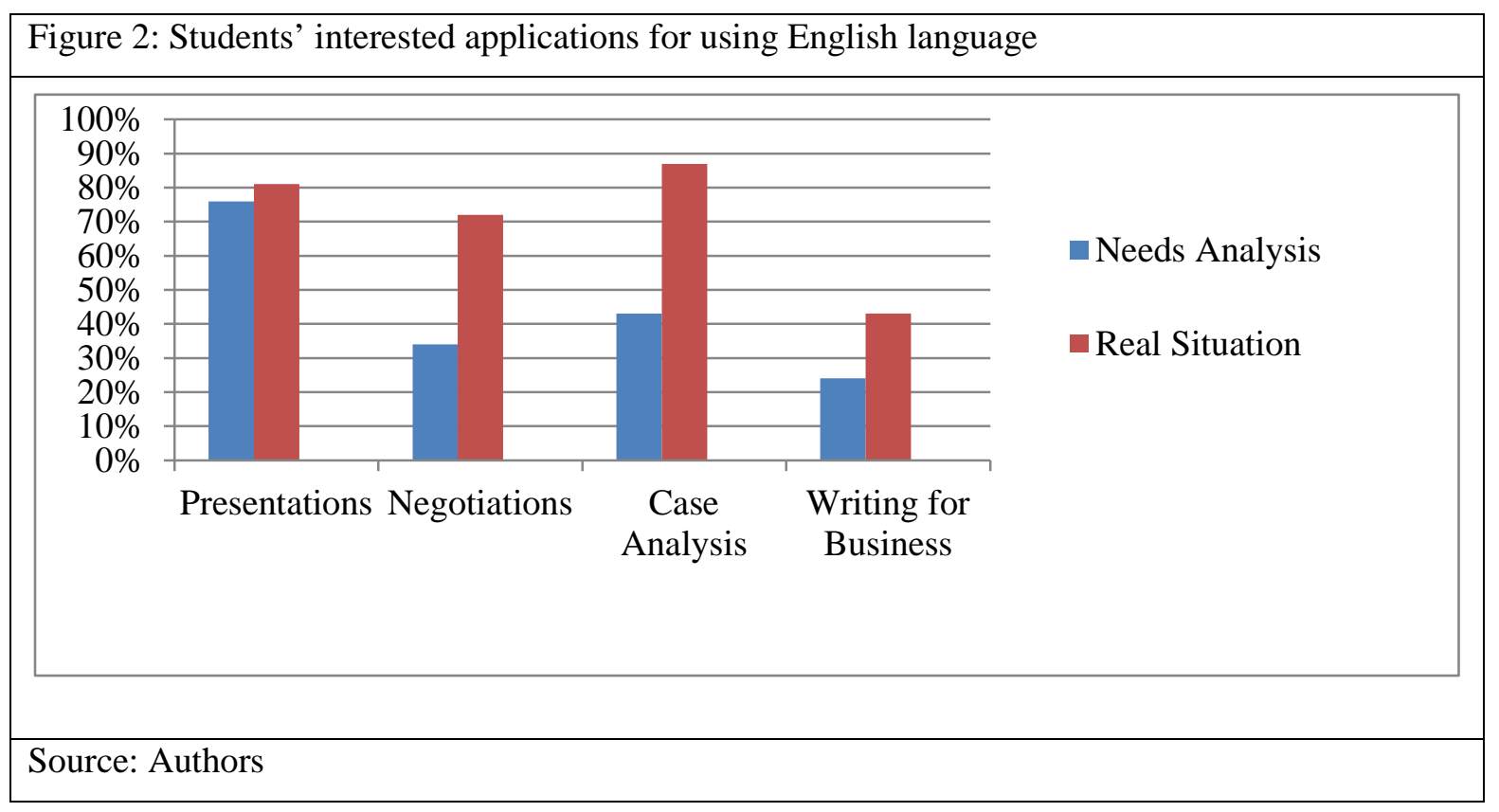

Figure 3: Students’ interested applications for using English language

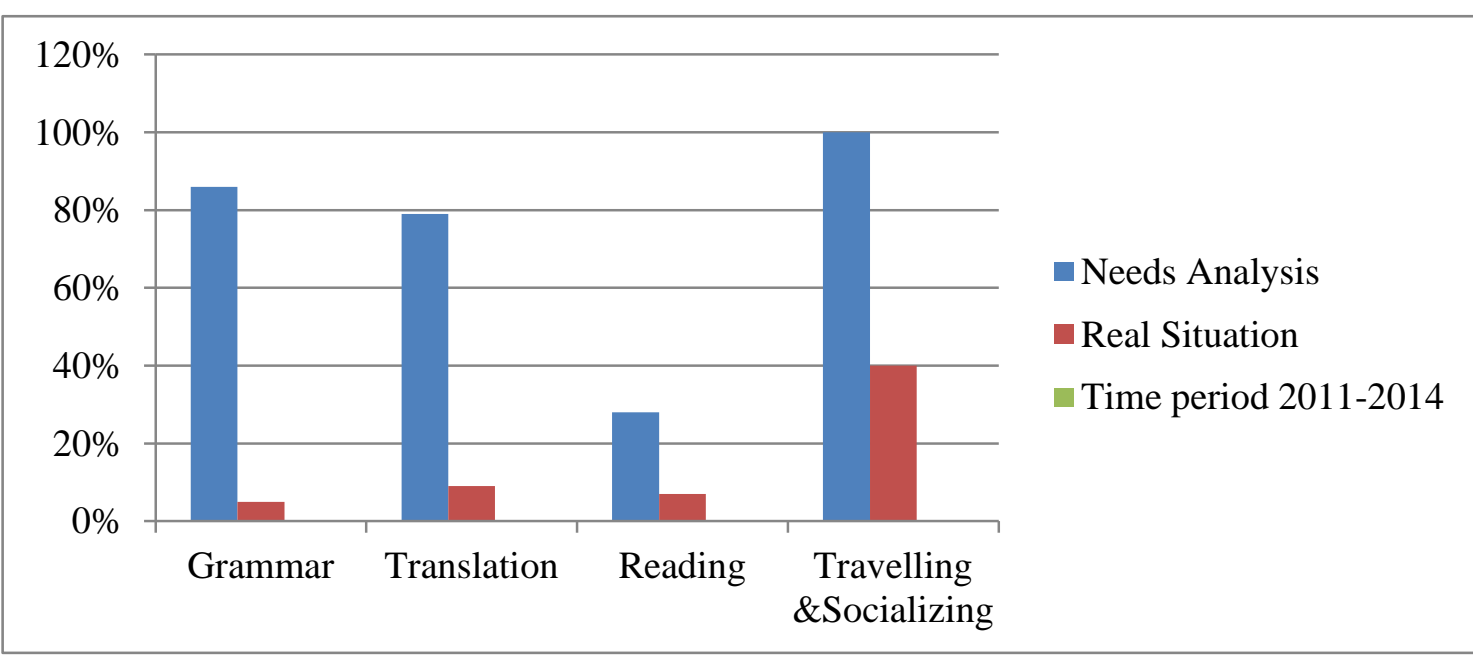

Source: Authors

To make students more involved in the process, we encourage peer evaluation and ask students to complete checklists (Table 1), while listening to their group members' presentations, which means that grading system is transparent and easy to apply. We believe that positive assessment received from both teachers (evaluating achievements in a foreign language proficiency) and fellow students (evaluating acquired presentation skills) provides better understanding of achieved progress and boosts students' confidence. 
CBU I NTERNATI ONAL CONFERENCE ON I NNOVATION, TECHNOLOGY TRANSFER AND EDUCATION

\begin{tabular}{|c|c|c|c|c|c|}
\hline \multicolumn{6}{|l|}{ Table 1: Checklist for Presentations } \\
\hline \multicolumn{6}{|l|}{ Theme/Topic: } \\
\hline Points of assessment & & Sco & ing & $1-5)$ & \\
\hline $\begin{array}{l}\text { - appropriateness } \\
\text { - clarity } \\
\text { - relevance to objectives of the presentation }\end{array}$ & 1 & 2 & 3 & 4 & 5 \\
\hline $\begin{array}{l}\text { 2. Content (1) } \\
\text { - adequacy } \\
\text { - depth }\end{array}$ & 1 & 2 & 3 & 4 & 5 \\
\hline $\begin{array}{l}\text { 3. Content (2) } \\
\text { - creativity } \\
\text { - originality/ individuality }\end{array}$ & 1 & 2 & 3 & 4 & 5 \\
\hline $\begin{array}{l}\text { 4. Structure } \\
\text { - organization (introduction, main part, } \\
\text { conclusion) } \\
\text { - signposting } \\
\text { - linking }\end{array}$ & 1 & 2 & 3 & 4 & 5 \\
\hline $\begin{array}{l}\text { 5. Visuals } \\
\text { - presentation is supported by adequate tools } \\
\text { (e.g. slides) } \\
\text { - creativity of design }\end{array}$ & 1 & 2 & 3 & 4 & 5 \\
\hline $\begin{array}{l}\text { 6. Delivery } \\
\text { - presentation skills } \\
\text { - body language }\end{array}$ & 1 & 2 & 3 & 4 & 5 \\
\hline $\begin{array}{l}\text { 7. Audience rapport } \\
\text { - awareness } \\
\text { - enthusiasm }\end{array}$ & 1 & 2 & 3 & 4 & 5 \\
\hline Overall score: & & & & & \\
\hline Source: Authors & & & & & \\
\hline
\end{tabular}

\section{Impact of assessment system on students' motivation}

In developing the system of assessment, we focused on increasing students' motivation, encouraging their active participation in the training process, and creating positive and challenging environment for using a foreign (English) language. Furthermore, when selecting types of tasks for classes and assessments, we focused on the following characteristics for students' assignments:

- authentic;

- skill-applicable;

- challenging, but achievable;

- universal. 


\section{Authentic}

We selected texts and cases from up-to-date British sources, such as periodicals, companies' sites, and textbooks, thus ensuring that the tasks provided are meaningful and interesting for students and reflect current language trends.

\section{Skill-applicable}

The tasks require application of skills acquired in the course of studies, which, at the same time, are essential for successful performance in business environment (delivering presentations, taking parts in debates, being persuasive and informative, etc.)

\section{Challenging (but achievable)}

On the one hand, tasks offered should encourage students to do their best to achieve their goals. On the other hand, the assignments difficulty level should be adjusted to suite students' language proficiency in order not to demotivate them. Moreover, we believe that the level of task complexity has to encourage students' autonomy.

\section{Universal}

As long as our target students are employed in different areas of business, we ensured that all materials selected bear a universal character and do not require very specific knowledge in any narrow area of business.

\section{Conclusion}

In conclusion, we would like to emphasize that a proper selection of material and design of assignments for both classroom activities and final control and assessment can serve as a tool to increase students' motivation and facilitate studying process in heterogeneous groups of adults in further education programs.

\section{References}

Brown, J. D., \& Hudson, T. (2003) Criterion-referenced Language Testing. Cambridge, England: the Cambridge University Press.

Dornyel, D. (2010). Motivation Strategies in the Language Classroom. Cambridge, England: Cambridge University Press.

Harmer, J. (2007). The Practice of English Language Teaching. Pearson Education Limited, Edinburgh Gate.

Hess, N. (2004). Teaching Large Multilevel Classes. Cambridge, England: the Cambridge University Press.

Holliday, A. (1997). Appropriate Methodology and Social Context. Cambridge University Press.

Lantolf, J. P. (2004). Sociocultural Theory and Second Language Learning. Oxford University Press.

Luoma, S. (2011). Assessing Speaking. Cambridge University Press.

McKay, H., \& Tom, A. (2010). Teaching Adult Second Language Learners. Cambridge, England: Cambridge University Press.

Pintrich, P. R., \& Schunk, D. H. (2002). Motivation in Education. Upper Saddle River, New Jersey; Columbus, Ohio: Merrill Prentice Hall. 